\title{
BMJ Quality Understanding and overcoming barriers to timely discharge from the pediatric units
}

\author{
Amira Mustafa, Samar Mahgoub
}

To cite: Mustafa A, Mahgoub S. Understanding and overcoming barriers to timely discharge from the pediatric units. BMJ Quality Improvement Reports 2016:5:u209098.w3772 doi:10.1136/bmjquality. u209098.w3772

Received 10 March 2016 Revised 6 June 2016 Accepted 1 September 2016

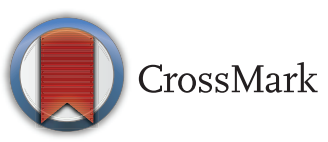

Hamad General Hospital, Qatar

Correspondence to amira mustafa amustafa4@ hamad.qa

\section{ABSTRACT}

Delays in the discharge of hospital patients cause a backlog for new admissions from the Emergency Departments (ED), outpatient clinics, and transfers from the Intensive Care Units (ICU). A variety of initiatives have been reported on previously which aim to tackle this problem with variable success. In this quality improvement project, we aimed to increase the proportion of discharged patients who leave the paediatric unit by $12: 00$ Noon from $7 \%$ to $30 \%$ by May 2015.

A baseline discharge process map was studied to understand the possible causes of the delays. A survey was conducted to look for the most likely cause for the delay. A data collection tool was designed to record the various steps in the discharge process for the pre-and post-intervention phases. Using a series of PDSA cycles, interventions were introduced.

The average time for the discharge process was two hours and the baseline average percent of patients discharged by $12: 00$ Noon was $7 \%$ of all discharges. The leading cause for the delayed discharges was late orders by the physicians. Post-intervention, there was increase in the percentage of patients discharged by $12: 00$ Noon from $7 \%$ to $34 \%$. $42 \%$ of discharged patients had appropriate reasons for afternoon discharge. By excluding these patients, the percentage of adjusted timely morning discharge has increased from $36 \%$ to $70 \%$.

Continuous monitoring and engagement of teams with regular feedback were the most important factors in achieving and sustaining improvement in the timely morning discharge of patients from our paediatric units.

\section{PROBLEM}

In this project, we examined delayed discharges in two of our paediatric units at Hamad General Hospital in Doha, Qatar. This hospital is a tertiary centre for the state of Qatar. We studied the discharge process, identified the barriers to discharge, and tested various interventions. The total bed capacity for the two paediatric units is 44 beds. In March 2013, only 7\% of discharged patients left the two paediatric medical units by noon. This created a bottleneck for new admissions from the emergency room and transfers out of paediatric intensive care. We aimed to increase our first measure, which was the percentage of discharged patients who left the two paediatric units by noon, from $7 \%$ in March 2013 to $30 \%$ by March 2015. Our analysis for discharged patients showed that a substantial number of patients were not eligible for morning discharge, hence a target of $30 \%$ was considered to be more realistic and achievable. By excluding those patients who were not eligible for morning discharge, we came up with the second measure. The second measure was the adjusted percentage for morning discharge; the proportion of patients who left by noon out of those eligible for morning discharge. Our aim for the second measure was to reach $50 \%$ by March 2015 .

\section{BACKGROUND}

Timely hospital discharge is a problem affecting many hospitals worldwide. ${ }^{1}$ While hospital administrators encourage the discharge of patients in the morning to expedite flow through the hospital, often discharges are clustered in the afternoon creating a mismatch between demand and availability of beds in the morning. ${ }^{2}$ This mismatch can cause significant overcrowding in the Emergency Department (ED) and will affect transfers from Intensive Care Units (ICU) and elective admissions. ${ }^{3} 4$ As a result of this many hospitals have adopted policies for early discharge. ${ }^{15}$ However, many patients may not be eligible for discharge in the morning for a variety of reasons and pushing too hard for morning discharge may mean that patients are held until the next morning when they could be discharged in the afternoon or evening. Many institutions currently discharge patients when they are ready ${ }^{6}$ rather than at a fixed time. The barriers to delayed discharge with different interventions have been studied and show a range of results. $^{7-9}$ The literature has addressed this 
problem of morning discharges with a lot of conflicting ideas and striking the right balance is the key for setting realistic targets for morning discharges.

Our institution is a tertiary teaching referral hospital for the state of Qatar. The Department of Paediatrics is one of the main clinical departments that provides medical services to the paediatric population (aged 0 to 14 years). The department is subdivided into paediatric medical, surgical, and intensive care with a capacity of 113 beds. The medical unit has three wards receiving admissions from all paediatric emergency centres, in addition to PICU transfers and admissions for elective procedures. The unit's admission rate was 5705/year in 2014. The paediatric beds are in high demand but there is a delay in patient discharges that impact the ED and paediatric ICU workflow.

\section{BASELINE MEASUREMENT}

A discharge team consisting of physicians, nurses, and case mangers was formed to study the problem in January 2013. The group studied the discharge process map (see fig 1). The process started with identifying the patient ready for discharge and ended with the patient leaving the unit. The discharge team then brainstormed causes for the delay in the discharge process (see fig 2). They designed an audit tool to record the various steps in the discharge process for the pre-and postintervention phases. Two quality reviewers collected data over two consecutive week periods on a monthly basis during the weekdays. Baseline measurement in March 2013 showed that only $7 \%$ of our patients had left by noon. 68 discharged patients were audited during the two week period in March 2013 using an audit tool to record the timings of the discharge process. The average time for discharge (from the physician ordering the discharge to the patient leaving the unit) was two hours. 93\% of the patients had discharge orders after 10am, $80 \%$ had late discharge summaries, $29 \%$ had late home medication arrival, and $41 \%$ had left late after all the paper work and instructions were given due to family and social reasons. The baseline measurements concluded that the leading cause for the delay was the physician delay in discharge and paperwork. Subsequently, a physician survey was conducted to look at the physicians' perceptions of the most likely causes for delay. 26 residents responded to the questionnaire out of a total of $35.35 \%$ of the physicians thought that the delay was due to no advanced paperwork preparation, 23\% thought

\section{Baseline Process Map}

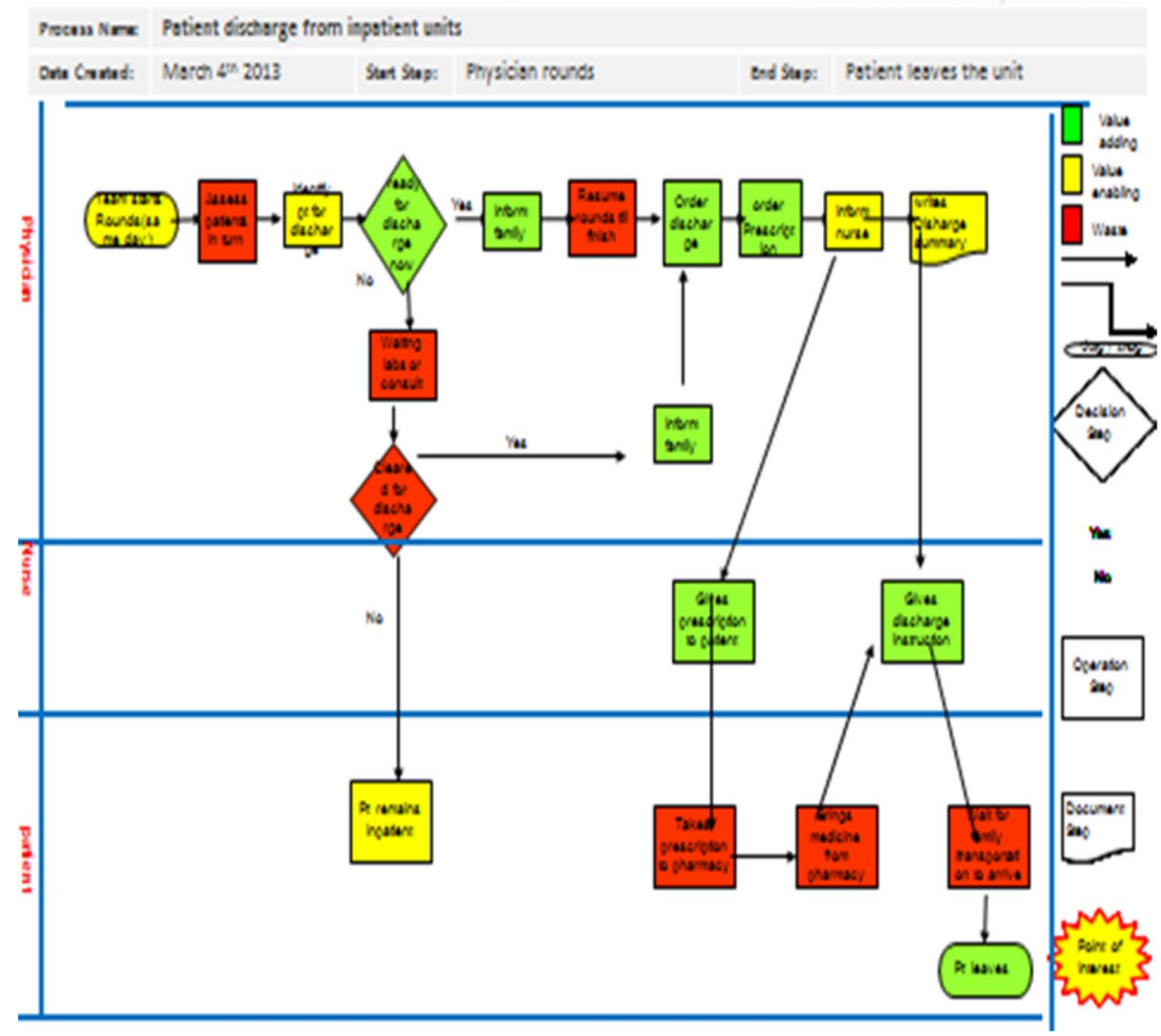

Fig 1. A baseline process map for the discharge process with value analysis of the steps using different color coding. 


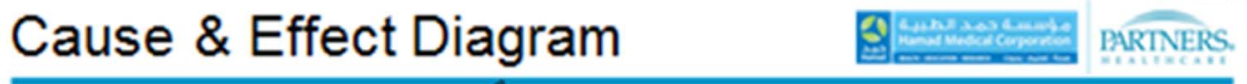

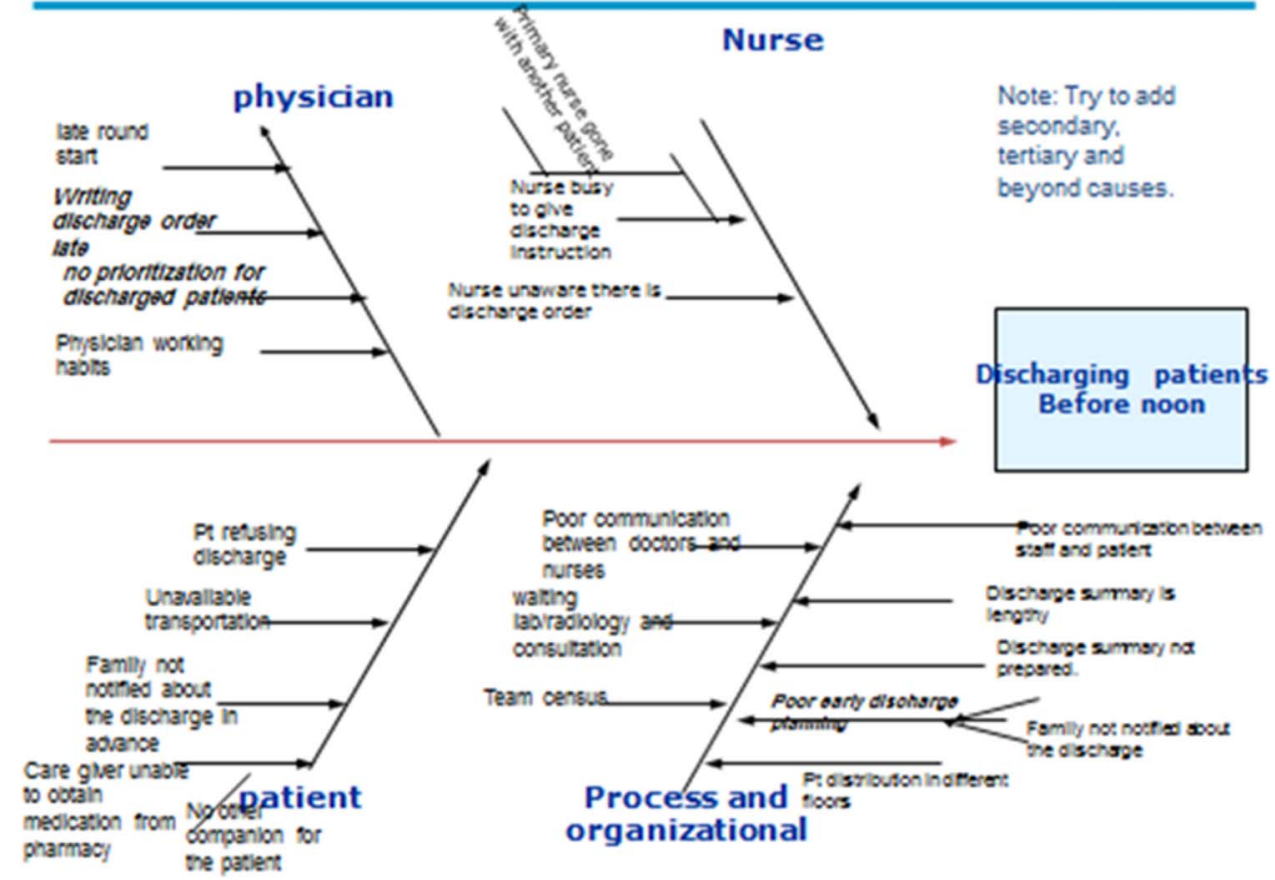

Fig 2. A fish bone diagram illustrating the possible causes for the delayed discharge.

that there was no prioritisation for discharge in morning rounds, $19 \%$ thought that family were not informed on time, and $8 \%$ thought that late round was the reason. We also audited the reason for patients leaving the unit after $12 \mathrm{pm}$. Patients who were kept past noon because of their medical condition and required further observation or treatment, or those who were awaiting procedures, tests or laboratory results, were considered as not eligible for morning discharge.

Measure 1 was calculated as the total number of patients who left by noon (Numerator) out of all discharges (denominator) audited during those two weeks. Measure 2 was calculated as the total number of patients who left before noon (numerator) out of those eligible or ready for morning discharge (denominator) during the two weeks period of observation. Monthly data was plotted in run charts throughout the study.

\section{DESIGN}

After analysing the data, a pareto chart was drawn to highlight the major causes of the delay in discharge process(see fig 3). The causes were physician delay in preparing the discharge paperwork in advance and a lack of prioritisation of discharged patients during rounds. The interventions were tailored to address these causes. A driver diagram was also crafted to plan the interventions. Key primary drivers were early discharge planning and prioritisation of discharged patients during morning rounds, (see fig 4).

Using quality improvement tools, six PDSA cycles were conducted over a 26 month period.

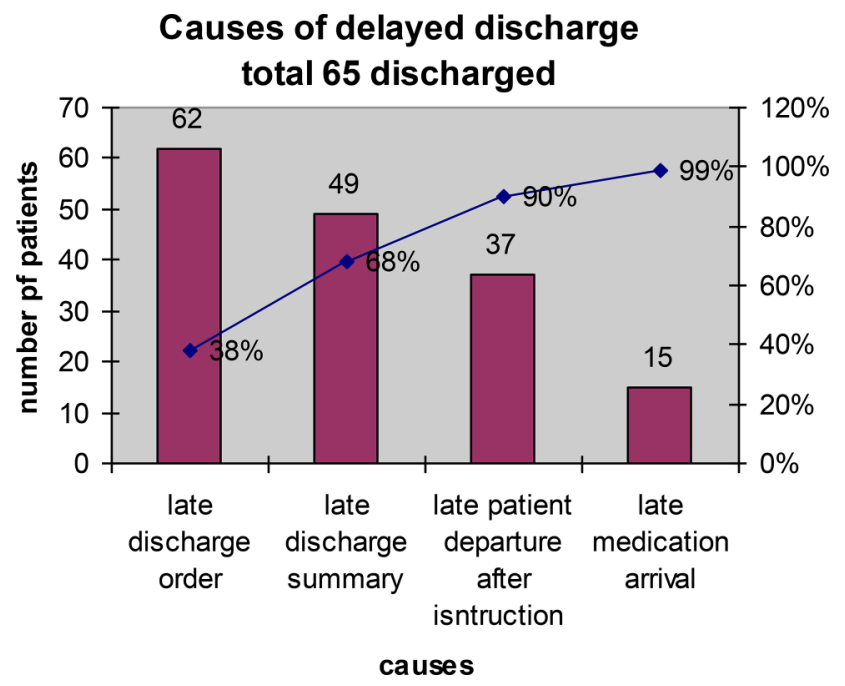

Fig 3. This a Pareto chart showing the data obtained from auditing the steps in the discharge process. It highlights the physician major role in delay of discharge.

\section{STRATEGY}

PDSA Cycle [Number 1]

Aim: Early discharge planning by:

1. Early identification of patient for possible discharge at least $24 \mathrm{hrs}$ in advance.

2. Preparation of discharge summary.

3. Checking of labs, consults equipment $24 \mathrm{hrs}$ in advance.

4. Patients for discharge are seen first during morning rounds.

5. Discharge orders and home prescriptions are written by $10 \mathrm{am}$. 


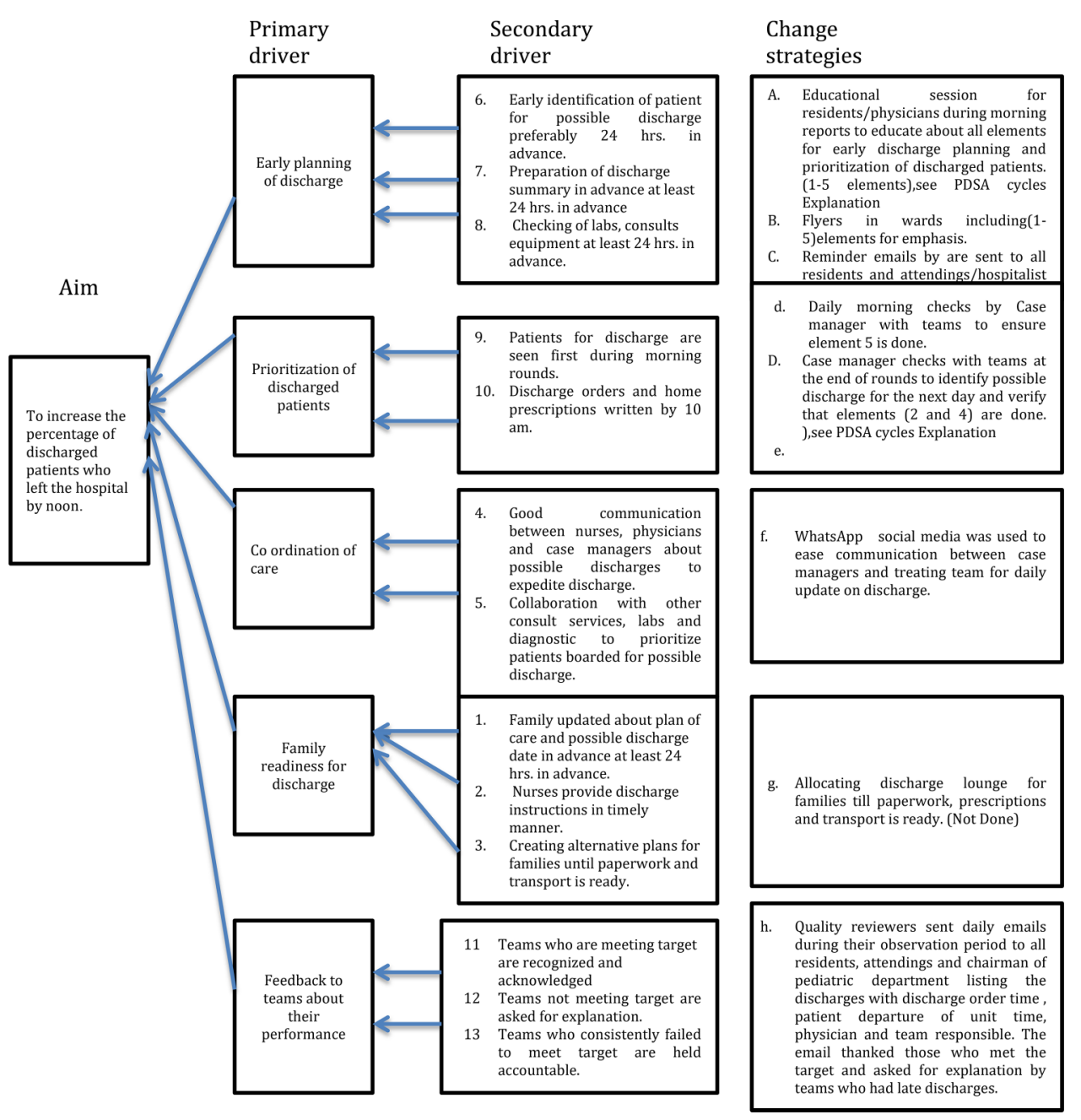

Fig 4. Key driver diagram for Timely Morning discharges for pediatric medical patients

Plan:

A. Educational session for residents/physicians during morning reports to educate about all elements for early discharge planning and prioritization of discharged patients. (1-5 elements)

B. Flyers in wards including (1-5) elements for emphasis.

C. Reminder emails by are sent to all residents and attending/hospitalist about elements (1-5)

D. Daily morning checks by Case manager with teams to ensure element 5 is done.

E. Case manager checks with teams at the end of rounds to identify possible discharge for the next day and verify that elements (2 and 4) are done.

Prediction: We predicted that the number of patients who had advance discharge preparation will leave early on their discharge day.

Do: Started in April 2013: There was good cooperation between physicians and case managers to accomplish this task. However treating teams needed daily reminders by case managers to be on top of this.

Study: This step has been successful initially raising the percentage of patients discharged before noon from
$7 \%$ in March 3013 to $25 \%$ in June 2013, but soon it started to wear off.

Act: Regular communication between case managers and treating teams is needed to ensure early discharge planning is conducted.

\section{PDSA Cycle [Number 2]}

Aim: Improve communication between nurses, physicians, and case managers about possible discharges to expedite discharge.

Plan: WhatsApp social media group was used to ease communication between case managers and treating team for daily update on discharge.

Prediction: Again we anticipated that this might improve communication and aid physicians to keep on task of early discharge planning.

Do: Started December 2014: residents reported that they are sometimes checking their messages at the end of the day and that this defeats the purpose.

Study: This step had been successful at initially raising the percentage of patients discharged before noon from $7 \%$ in March 2013 to $25 \%$ in June 2013, but soon after it started to wear off and was unable to sustain improvement. 
Act: Regular communication between case managers and treating teams is needed to ensure early discharge planning is conducted.

PDSA Cycle [Numbers 3 \& 4]

Aim: Reemphasis of early discharge planning by; 1 Discharge memo from paediatric chairman to all paediatric staff to emphasise early discharge planning using the 5 elements for discharge as in cycle 1 .

Plan: The discharge memo from the chairman of the paediatric department was sent to all pediatric staff. Reeducation of residents during morning reports and by emails to emphasise interventions needed as in cycle 1 (elements 1-5).

Prediction: We predicted that the staff would have better compliance with advance discharge preparation and hence patients would leave before noon.

Do: Cycle 3 commenced in March 2014.

Cycle 4 started August 2014 this was needed to target new joining residents in July.

All pediatric staff informed and all residents were reeducated regarding early discharge planning.

Study: Again following the drop down in July and August this intervention has helped lifting the percentage from 10\% in August to 22\% in September 2014.

Act: Education and reminders were not sufficient to achieve and sustain improvement, feedback to staff about their performance and accountability is needed.

PDSA Cycle [Number 5]

Aim: Sharing data with treating teams for feedback to improve performance;

Teams who are meeting target are recognized and acknowledged

Teams not meeting target are asked for explanation.

Teams who consistently failed to meet target may be held accountable.

Plan: Quality reviewers to monitor and list the discharges with discharge order time, patient departure of unit time, physician, and team responsible during their observation period and share by email to all residents, consultants, with cc to chief resident.

Prediction: We predicted that the number of patients who left the unit before noon would increase due to physician awareness about their performance. We predicted that the acknowledgement would give them an incentive to meet the target.

Do: Cycle 5; September 2014, Quality reviewers send daily emails during their observation period to all residents, rounding consultants and chairman of paediatric department. The email thanked those who met the target and asked for an explanation from teams who had late discharges. Those who were consistently not complying with this target and without justified reason were informed that they would be held accountable.

Study: Cycle 5: This intervention brought the biggest difference in October 2014 raising the percentage to $34 \%$ out of total discharges and reaching $70 \%$ for those who were eligible for morning discharge. Failure of consistency in regular feedback has resulted in a decline afterwards.

Act: This feedback and acknowledgement should be done regularly. It was also felt that no disciplinary action should to be taken for noncompliance to avoid negative working atmosphere.

PDSA Cycle [Number 6]

Aim: Regular sharing data with treating teams for feedback to improve performance; focusing on positive enforcement only. Teams who are meeting targets are recognised and acknowledged. Teams not meeting targets are asked for an explanation.

Plan: Quality reviewers to monitor and list the discharges with discharge order time, patient departure of unit time, physician, and team responsible during their observation period and share by email to all residents, consultants with cc to chief resident.

Prediction: We predicted that the number of patients who left the unit before noon would increase due to physician awareness about their performance. We predicted that the acknowledgement would give them an incentive to meet the target.

Do: Cycle 6; February 2015, Quality reviewers send daily emails during their observation period to all residents, rounding consultants. The email thanked those who met the target and asked for explanation by teams who had late discharges.

Study: This has brought consistent improvement during the last three months of the study raising the percentage to 25\% in March 2015, 29\% in April 2015, and $26 \%$ in May 2015.

Act: Cycle 6 brought more consistent change without putting too much pressure on treating teams. This however did not reach to the same level that was reached after cycle 5 which was $34 \%$. Continuous and rigorous feedback about performance is needed to sustain this gain and reach our target which was $30 \%$.

\section{RESULTS}

Our interventions showed remarkable improvements following some PDSA cycles interrupted by periods of decline for both measure 1 (see fig 5) and measure 2 (see fig 6 ). Measure 1 is the percentage of patients who left by noon out of the total discharged. Measure 2 is the number of patients who left the unit out of those ready for morning discharge. As mentioned earlier a substantial number of patients were not candidates for morning discharge and by excluding them, the second measure was calculated. We reviewed the two months of data for discharged patients in April and May 2014. A total of 109 discharges were audited, $13 \%$ of patients were kept because of their medical condition, $18 \%$ were awaiting procedures and tests on the discharge date, and $11 \%$ had pending lab results which were needed prior to discharge (see Fig.7).

The first PDSA cycle in April-May 2013 increased the percentage of patients who left the unit by 12 Noon 
Percentage of patients who left the pediatric units at or before noon

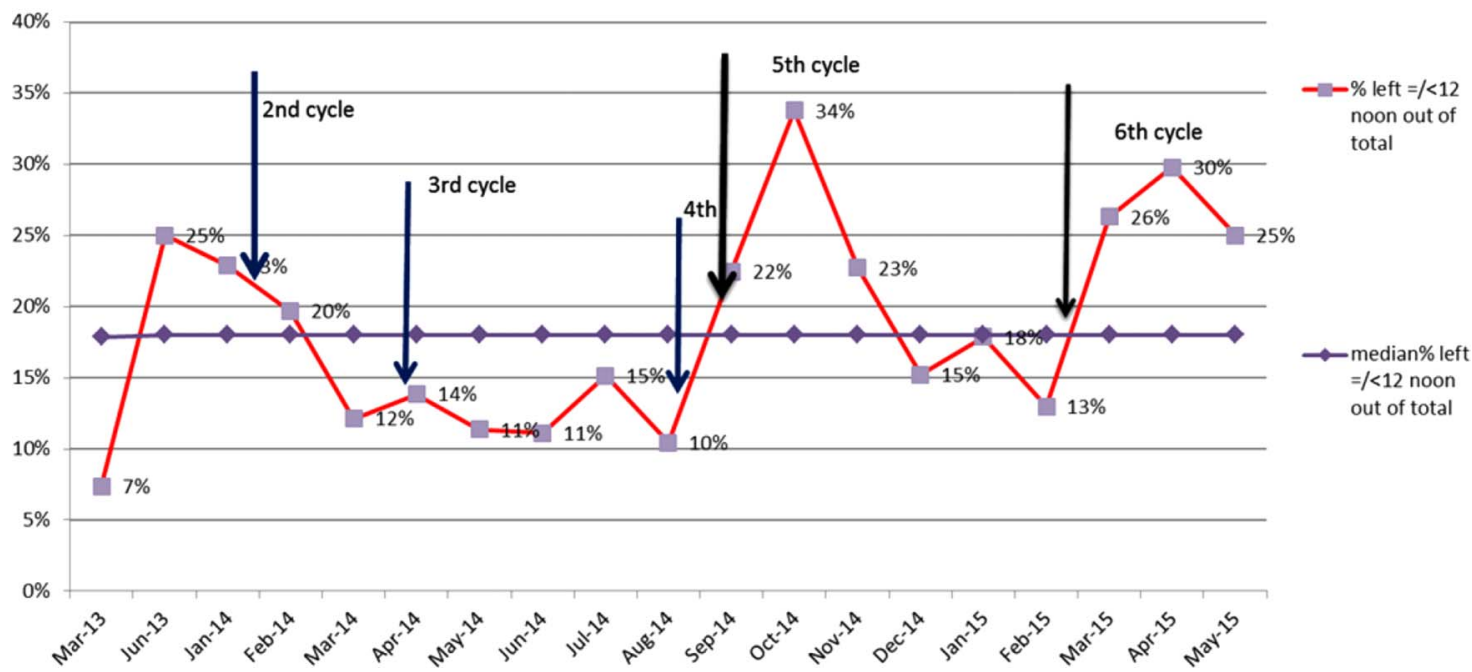

Figure 5: Run chart for measure 1 (percentage of patients who left the unit by noon out of the total discharges). This shows the results for measure 1 starting in March 2013 (pre- intervention phase) followed by multiple PDSA cycles over 26 months

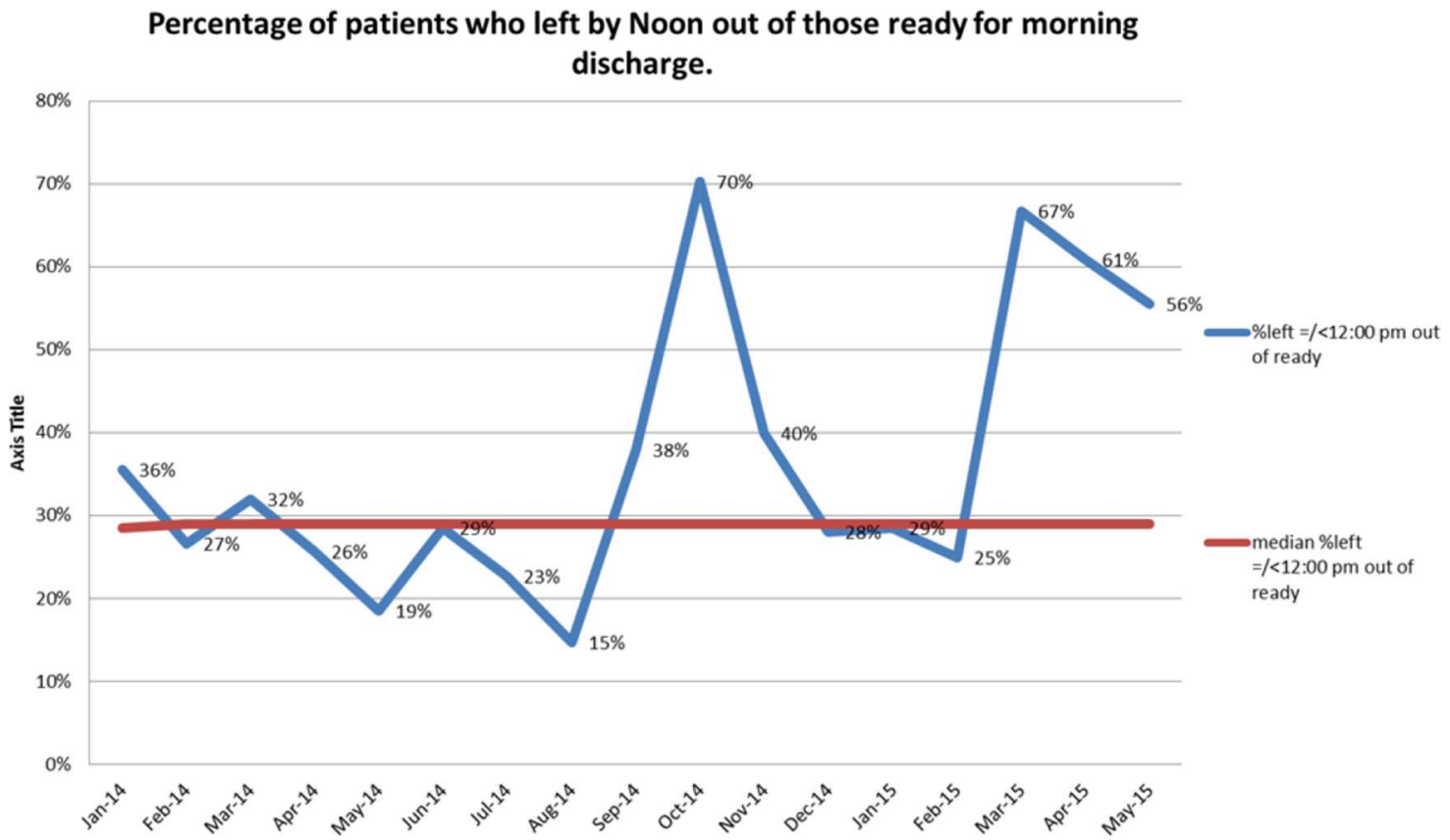

Figure 6: Run chart for measure 2 (adjusted timely morning discharge which is the percentage of patients who left by noon out of those eligible for morning discharge and left by noon).

from 7\% (measure 1) in March 2013 to $25 \%$ in June 2013 (measure 1). The second PDSA cycle in December 2013 helped to keep the percentage of morning discharge at 23\% (measure 1) and $35 \%$ (measure 2). Following that there was a steady decline in performance reaching $12 \%$ in March 2014. The third PDSA cycle in April 2014 made no difference for both measures and the fourth PDSA cycle in August 2014 was able to increase the percentage to $22 \%$ (measure 1) and $38 \%$ (measure 2). The fifth PDSA cycle in September 2014 brought about the most remarkable change reaching $34 \%$ for measure 1 and $70 \%$ for measure 2 exceeding our target. The sixth PDSA in February 2015 resulted in a steady increase to $26 \%$ (measure 1) and $67 \%$ (measure 2) in March, 29\% (measure 1) and 61\% (measure 2) in April, and 25\% (measure 1) and 56\% (measure 2) in May 2015. It is worth mentioning that there was no increase in the average length of stay for both units for the period when timely discharge was improved. 


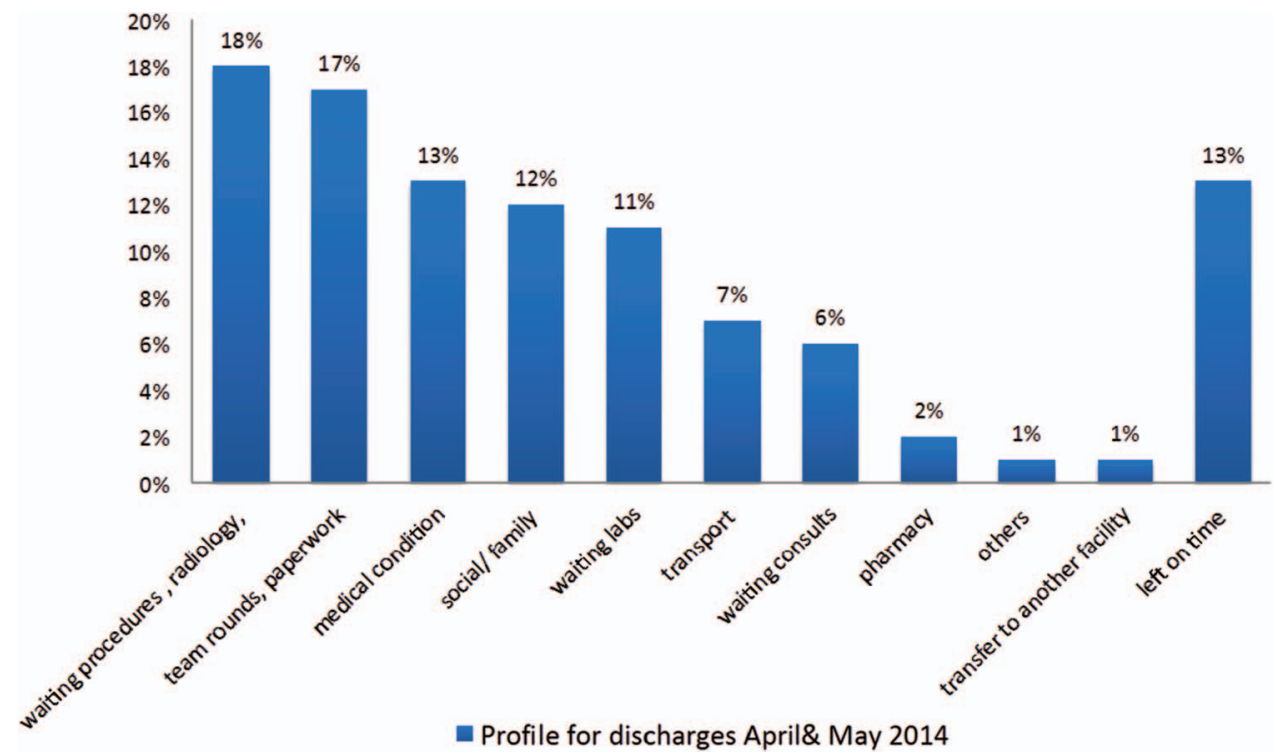

Figure 7: Discharge profile explaining the reasons for discharges in the afternoon during April and May 2014, total discharges observed 109.

\section{LESSONS AND LIMITATIONS}

Our series of interventions has produced variable results. We surpassed our goal for measure 1, whereby we increased the percentage of discharges by noon from $7 \%$ in the pre-intervention phase to $34 \%$ (measure 1) in the paediatric units in October 2014. This was due to the changes in Cycle 5, which focused on prompt and regular feedback for treating teams together with acknowledgment and recognition for good performance and self-reflection for poor performance. Another factor that could have added to the improvement was the initial proposal of holding regular poor performers accountable. This latter part was withdrawn as it brought in negative re-enforcement and it was felt that it could result in discouragement in the long run. We did not test our interventions on a small scale before rolling them out across the department and some of the PDSA cycles have multiple interventions in them which means that we cannot be certain which of the interventions led to a change.

Understanding the reasons for discharge in the afternoon was key for setting a reasonable goal and allowing us to strike the right balance. In our units, $13 \%$ of patients were kept because of medical conditions, $18 \%$ were awaiting procedures and tests on the discharge date, and $11 \%$ had pending labs results needed prior to discharge. These amounted to a total of $43 \%$ who are not candidates for morning discharges and hence setting a goal for morning discharge above $50 \%$ would have been unrealistic. Setting a very high goal has the potential of increasing the length of stay for those patients are kept till the next morning when they could have been discharged in the afternoon or evening.

Since not all patients are candidates for morning discharges as discussed before then, measure 2 , will give a better reflection of timely morning discharges.
The barriers to delayed discharge have been studied and show various results. ${ }^{7}$ Wertheimer et al reported on their successful efforts that increased the percentage of pre-noon discharges from $11 \%$ to $38 \%$ in their medical units ${ }^{9}$; this was close to our result. Katz has discussed different opinions from a range of institutions for putting discharge on the clock with its pros and cons. ${ }^{6}$

Our study was limited in linking this goal to other hospital metrics like length of stay in the emergency department, duration of transfer out of PICU, as they would represent important outcome measures related to the process. We also experienced periods of decline in performance due to lack of prompt feedback of results to the teams. The process of regular feedback is time consuming and this in itself might be the limiting factor for sustainability. However if this process becomes automated in the era of electronic records it should be easier to do. This was a small study at our institution; this could be replicated at other institutions, however it does depend on setup, process, population, amongst other factors.

We did not test our interventions on a small scale before rolling them out across the department and some of the PDSA cycles have multiple interventions in which means that we cannot be certain which of the interventions led to a change.

\section{CONCLUSION}

Timely morning discharge remains a challenge; however our interventions were able to produce improvement. Setting a reasonable goal for different units is essential and achievable. Continuous monitoring and regular feedback to the team were the most effective intervention in achieving and sustaining the improvement result. Further projects which focus on other factors affecting discharge are needed to further enhance and sustain timely discharge. 
Acknowledgements Mini Ramesh, Zenat Kanfosh, Reda Ezzeldin, Ibtesam Mohd, Safa Mohamed, Amal Aly, and Samar Yagoub.

Declaration of interests None declared

Ethical approval This work is primarily intended to improve local care, not provide generalizable knowledge in a field of inquiry. The academic health system at Hamad Medical Corporation has an agreement with BMJ Quality reports for submission of these quality reports.

Open Access This is an open-access article distributed under the terms of the Creative Commons Attribution Non-commercial License, which permits use, distribution, and reproduction in any medium, provided the original work is properly cited, the use is non commercial and is otherwise in compliance with the license. See:

- http://creativecommons.org/licenses/by-nc/2.0/

- http://creativecommons.org/licenses/by-nc/2.0/legalcode

\section{REFERENCES}

1. Department of Health, United Kingdom. Achieving timely simple discharge from hospital: A toolkit for the multi-disciplinary team, 2004. http://www.dh.gov.uk/en/Publicationsandstatistics/
2. Powell ES, Khare RK, Venkatesh AK, Van Roo BD, Adams JG, Reinhardt $\mathrm{G}$. The relationship between inpatient discharge timing and emergency department boarding. J Emerg Med. 2012; 42: 186-96.

3. Howell E, Bessman E, Kravet S, Kolodner K, Marshall R, Wright S. Active bed management by hospitalists and emergency department throughput. Annals of Internal Medicine, 2008: 149:804-810

4. Litvak E, Long MC, Cooper AB, McManus ML. Emergency department diversion: Causes and solutions. Academic Emergency Medicine, 2001:8: 1108-1110

5. Birjandi A, Bragg LM. Discharge Planning Handbook for Healthcare: Top 10 Secrets to Unlocking a New Revenue Pipeline. New York: Productivity Press, 2008

2. Katz PS. Need to speed up Discharges? The pros and cons of putting discharges on the clock. Today's Hospitalist. December 2013.

7. Clark JJ. Unlocking hospital gridlock. Healthcare Financial Management. 2005:59:94-98

8. Maguire P. Building a better discharge: Three case studies on discharge innovation, Today's Hospitalist, July 2011

9. Wertheimer B, Jacobs RE, Bailey M, et al. Discharge before noon: an achievable hospital goal. J Hops Med, 2014: 9: 210-214 